\title{
Medical education and mental health during COVID-19: a survey across 9 countries
}

\author{
Daniel Michaeli' ${ }^{1}$, Gregory Keough ${ }^{2}$, Francisco Perez-Dominguez ${ }^{3}$, Francisca Polanco-Ilabaca ${ }^{3}$, \\ Fernanda Pinto-Toledo ${ }^{3}$, Julia Michaeli ${ }^{4}$, Sebastian Albers ${ }^{5}$, Jadi Achiardi', Valeria Santana ${ }^{7}$, \\ Chiara Urnelli ${ }^{8}$, Yoshihiro Sawaguchi ${ }^{9}$, Perla Rodríguez ${ }^{10}$, Mónica Maldonado ${ }^{11}$, Zaheer Raffeeq ${ }^{12}$, \\ Otavio de Araujo Madeiros ${ }^{13}$, Thomas Michaeli ${ }^{14}$
}

\begin{abstract}
${ }^{1}$ Department of Personalized Oncology, University Hospital Mannheim, Heidelberg University, Mannheim, Germany
${ }^{2}$ Department of Health Policy, London School of Economics and Political Sciences, London, United Kingdom

${ }^{3}$ Escuela de Salud Pública, Facultad de Medicina, Universidad de Chile, Santiago, Chile

${ }^{4}$ Department of Obstetrics and Gynecology, Asklepios-Clinic Hamburg-Altona, Asklepios Hospital Group, Hamburg, Germany

${ }^{5}$ Department of Orthopedic Surgery, ATOS Klinik Fleetinsel Hamburg, Hamburg, Germany

${ }^{6}$ Facultad de Medicina y Ciencias de la Salud, Universidad Militar Nueva Granada, Bogotá, Colombia

${ }^{7}$ Escuela Luis Razetti, Universidad Central de Venezuela, Caracas, Venezuela

${ }^{8}$ Facoltà di Medicina e Chirurgia, Università degli Studi del Piemonte Orientale, Novara, Italy

${ }^{9}$ Faculty of Medicine, Tokyo Medical and Dental University, Tokyo, Japan

${ }^{10}$ Facultad de Medicina, Universidad Panamericana, Ciudad de México, Mexico

${ }^{11}$ Facultad de Medicina, Universidad de Sevilla, Sevilla, Spain

${ }^{12}$ Humanitas University - Hunimed, Milan, Italy

${ }^{13}$ Faculdade de Ciências Médicas Santa Casa de São Paulo, São Paulo, Brazil

${ }^{14}$ Fifth Department of Medicine, University Hospital Mannheim, Heidelberg University, Mannheim, Germany
\end{abstract}

Correspondence: Daniel Michaeli, Heidelberg University, University Hospital Mannheim, Mannheim, Germany

Email: danielmichaeli@yahoo.com

Accepted: February 13, 2022

\begin{abstract}
Objectives: To investigate students' experience with medical education alongside their mental and physical health since the onset of the COVID-19 pandemic across nine countries. Methods: A cross-sectional online survey was distributed by local collaborators to 2,280 medical students across 148 medical schools in Brazil, Chile, Colombia, Germany, Italy, Japan, Mexico, Spain, and Venezuela using non-probability convenience sampling from June 22 to July 24, 2020. Students answered questions regarding teaching, internet use, COVID-19, physical and mental well-being. A multivariate logistic regression examined factors associated with depressed mood, insomnia, and headache.
\end{abstract}

Results: Academic teaching shifted to a virtual (67\%, $\mathrm{n}=1,534)$ or hybrid environment $(23 \%, \mathrm{n}=531)$, whilst bedside teaching was suspended or cancelled $(93 \%, n=2,120)$. Across all countries students were equally satisfied with the teaching modality, quantity, quality, and the evaluation system of in-person, hybrid, and online curricula. Negative changes in mental $(40 \%(n=912)$ insomnia, $57 \%(n=1,300)$ emotional irritability, $47 \%(\mathrm{n}=1,072)$ emotional instability, $41 \%(\mathrm{n}=935)$ anhedonia, 40\% ( $\mathrm{n}=912)$ depressed mood) and physical $(36 \%(n=821)$ headache, 57\% $(n=1,299)$ ocular tiredness, $49 \%(\mathrm{n}=1,117)$ backache) health symptoms were frequently observed. Positive associations between the number of daily screen hours and depressed mood (adjusted odds ratio $(\mathrm{AOR})=1.09,95 \% \mathrm{CI}: 1.05-1.12, \mathrm{p}<.001)$, insomnia $(\mathrm{AOR}=1.08,95 \% \mathrm{CI}: 1.05-1.11, \mathrm{p}<.001)$, and headache $(\mathrm{AOR}=1.11,95 \% \mathrm{CI}: 1.07-1.14, \mathrm{p}<.001)$ were identified.

Conclusions: Students' experience with digital and hybrid medical curricula was diverse during the pandemic. Education modality, quantity, and quality were positively evaluated. However, students' mental and physical health worsened. Besides bedside teaching, faculties ought to digitalize and strengthen social communities and extend support services for students.

Keywords: COVID-19, mental health, medical student, depression, insomnia 


\section{Introduction}

Similar to previous outbreaks, the COVID-19 pandemic and its consequent policy responses disrupted social and professional life. ${ }^{1-5}$ While university hospitals focused on providing care to patients, medical education and students' well-being were deprioritized. Since the pandemic's onset medical schools unavoidably adjusted academic curricula in order to adhere to social distancing, safety, and health policies. ${ }^{6,7}$ Most schools shifted to online teaching with a reduction or even suspension of practical teaching. ${ }^{6-8}$ Practical exams, such as objective structured clinical examination (OSCE), were replaced with online, open-book exams. ${ }^{9-11}$ Consequently, students faced uncertainty surrounding prolonged studies, delayed graduation, and feared a cancellation of residency programmes. ${ }^{11,12}$ Not only did this change complicate academic learning, but it also disrupted social peer networks of students. ${ }^{7,13}$ As well informed and educated future healthcare professionals, students were frequently mobilized and fasttracked to support shortages in medical staff., 9, 14-16 Nevertheless, some authors embraced the long-overdue disruption of rigid education systems towards a hybrid, practical and/or virtual curriculum. ${ }^{17-20}$ Some specialties, e.g., otolaryngology or elective surgery, suffered disproportionally from immediate and future effects. ${ }^{7,12,21-23}$ In conclusion, the pandemic presented as an unexpected, disruptive external shock to medical schools and students. Theoretically, the resulting uncertainty and turmoil of academic curricula, future career prospects, and social networks may adversely affect mental health. However, the association of these academic and social changes triggered by the pandemic on mental health remain unclear.

Numerous studies revealed the pandemic's harmful impact on mental health. ${ }^{2-5,24}$ Proximity to high-risk areas, especially for medical personal and students, was frequently identified as a key risk factor for deteriorating mental wellbeing. ${ }^{25-30}$ Surveys in China, Vietnam, Australia, and Saudi Arabia previously investigated the prevalence and risk factors associated with mental health disorders among medical students during COVID-19. Depression was frequently associated with risk factors such as female sex, pessimistic thoughts, and anxiety disorders. ${ }^{31,32}$ Anxiety and insomnia were significantly increased among graduate students with pessimistic thoughts and depression who lived in high-risk regions. ${ }^{31,32}$ Mental distress was even more prevalent and associated with direct COVID-19 infection, infected relative, alcohol consumption, smoking, female sex, low health literacy, and recent enrolment. ${ }^{33,34}$ However, present research investigating medical student's psychological health is limited in geographical scope and size. ${ }^{31-37}$

To the best of our knowledge, there is no study that thoroughly examines medical students' experience and well-being during the COVID-19 pandemic. Consequently, the present study fills this research gap by investigating and contrasting medical students' experiences during the COVID-19 pandemic across nine countries (Brazil, Chile,
Colombia, Germany, Italy, Japan, Mexico, Spain, and Venezuela). The objective of this study is twofold:

- First, we aimed to describe changes in medical education since the onset of the pandemic and to compare how well students perceived different teaching modalities (online, hybrid, in-person) during the pandemic.

- Second, we aimed to examine changes in students' study habits, mental health, physical health, and substance use since the onset of the pandemic. Within this, we intended to identify factors associated with negative changes in depressed mood, insomnia, and headache.

\section{Methods}

\section{Study design and participants}

A cross-sectional study was conducted from June 22 to July 24,2020 . First, a multidisciplinary group composed of medical students, public health doctors, a mathematic engineer, and a psychologist designed a five-part online survey. The Spanish survey was translated into five different languages (English, German, Italian, Portuguese, Japanese) by official interpreters. Non-probability sampling using convenience sampling technique was employed to acquire 2,280 full survey responses from medical students.

\section{Demographic characteristics}

The analysis includes 2,280 completed survey responses (completion rate: 79.7\%) from Brazil (157), Chile (565), Colombia (260), Germany (550), Italy (169), Japan (150), Mexico (124), Spain (122), and Venezuela (183). 68\% $(n=1,545)$ identified as female, $31 \%(n=710)$ as male, and $1 \%(n=25)$ as other. The average medical student was 22.5 years old and enrolled in the third year of medical school. Across the entire sample, $16 \%(n=370)$ of students were involved in the care of COVID-19 patients. Medical students from Germany (36\%, $\mathrm{n}=198)$ were more, while those from Japan ( $3 \%, \mathrm{n}=5)$, Mexico $(5 \%, n=6)$, Spain $(2 \%, n=2)$, and Venezuela $(8 \%, n=15)$ less frequently involved in the care of infected patients $\left(\chi^{2}{ }_{8}\right.$ $\mathrm{N}=2,280)=237.43, \mathrm{p}<.001)$. Baseline characteristics are presented in Table 1.

All respondents acknowledge to be registered medical students. While medical education lasts six years in all surveyed countries, the curriculum's structure varies across nations. In Germany, Spain, Colombia, and Chile, the medical curriculum consists of two pre-clinical and four clinical years. In contrast, Japanese students are educated for four years on pre-clinical and two years on clinical subjects. In Italy and Venezuela, students go through three years of theoretical and three years of clinical education. The last year of medical school is mostly dedicated to clerkships and medical internships to gain practical experience. Nonetheless, even within countries, there are discrepancies of the employed medical curriculum across faculties. For instance, some faculties in Germany employ an integrated curriculum, e.g., 
Table 1. Baseline characteristics of the survey sample

\begin{tabular}{|c|c|c|c|}
\hline \multicolumn{2}{|l|}{ Variable } & No. & $(\%)$ \\
\hline \multicolumn{4}{|l|}{ Gender } \\
\hline & Male & 710 & $(31)$ \\
\hline & Female & 1,545 & $(68)$ \\
\hline & Other & 25 & $(1)$ \\
\hline \multicolumn{2}{|c|}{ Age, mean $(y)^{a}$} & 22.5 & {$[22.4-22.7]$} \\
\hline \multicolumn{2}{|c|}{ Year of study, mean $(y)^{a}$} & 3.61 & [3.54-3.69] \\
\hline \multicolumn{2}{|c|}{ Screen time, mean $(\mathrm{h})^{a}$} & 9.68 & {$[9.54-9.82]$} \\
\hline \multicolumn{4}{|c|}{ Teaching modality } \\
\hline & No teaching & 150 & (7) \\
\hline & In-person & 65 & (3) \\
\hline & Hybrid & 531 & $(23)$ \\
\hline & Online & 1,534 & (67) \\
\hline \multicolumn{4}{|c|}{ Academic duration } \\
\hline & Unchanged & 956 & $(42)$ \\
\hline & Changed / postponed & 1,324 & (58) \\
\hline \multicolumn{4}{|c|}{ No. academic evaluations } \\
\hline & Unchanged & 1,256 & $(55)$ \\
\hline & Changed / postponed & 1,024 & $(45)$ \\
\hline \multicolumn{4}{|c|}{ Practical activities } \\
\hline & Unchanged & 160 & (7) \\
\hline & Reduced & 826 & $(36)$ \\
\hline & Suspended & 1,294 & $(57)$ \\
\hline \multicolumn{4}{|c|}{ Thought about postponing studies? } \\
\hline & No & 1,372 & $(60)$ \\
\hline & Yes & 908 & $(40)$ \\
\hline \multicolumn{4}{|c|}{ Cared for COVID-19 patients? } \\
\hline & No & 1,910 & $(84)$ \\
\hline & Yes & 370 & $(16)$ \\
\hline \multicolumn{4}{|l|}{ Country } \\
\hline & Brazil & 157 & (7) \\
\hline & Chile & 565 & $(25)$ \\
\hline & Colombia & 260 & $(11)$ \\
\hline & Germany & 550 & (24) \\
\hline & Italy & 169 & (7) \\
\hline & Japan & 150 & (7) \\
\hline & Mexico & 124 & (5) \\
\hline & Spain & 122 & (5) \\
\hline & Venezuela & 183 & (8) \\
\hline Overall s & & 2,280 & $(100)$ \\
\hline
\end{tabular}

a Brackets represent $95 \%$ confidence intervals

Medical Faculty Mannheim of Heidelberg University, whereas others follow traditional teaching structures. Across all surveyed countries, students generally commence medical school directly after high school. However, students can also take gap years or pursue a paramedic apprenticeship before starting medical education - ultimately impacting the age at which students enter school.

The study was approved by the "Ethical Committee in Human Beings of the University of Chile." The survey also followed Chilean law No 20.584 that regulates people's rights and duties regarding the actions linked to health care and respects the international norms of data protection by the Organization of American States. All participants gave written online consent before starting the survey. To ensure confidentiality, all responses were anonymized.

\section{Measures}

The five-part survey consisted of 41 items lasting approximately ten minutes. The first part collected demographic characteristics regarding age, gender, year of study, country, university, and satisfaction with their internet connection. Satisfaction was measured on a scale from 1 to 5 (1: very satisfied, 2: satisfied, 3: indifferent, 4: unsatisfied, 5: very unsatisfied). The second part asked questions about the student's academic program, including changes in study modality, duration of the current year, evaluations, and practical activities. Participants were questioned about their current learning and study experience in the third part. Student's satisfaction with teaching modality, quantity, quality, the valuation system, academic burden, academic achievement, and the school's employed sanitary measures was measured on a scale from 1 to 5 (1: very satisfied, 2: satisfied, 3: indifferent, 4: unsatisfied, 5: very unsatisfied).

The fourth part investigated physical and mental health. Participants were asked about perceived changes in lifestyle habits (sleep, eating, weight), mental health (insomnia, emotional irritability, emotional instability, anhedonia, depressed mood), and physical health (headache, ocular tiredness, backache). For each outcome, students could report positive, negative, and neutral changes. Questions also addressed the use of substances and drugs (alcohol, tobacco, cannabis, other drugs, antidepressants, psychostimulants). For each item, students could select between decreased, increased, and unchanged consumption. The fifth part contained pandemic-related questions, e.g., engagement in the care for COVID-19 patients.

The survey was tested $(\mathrm{n}=50)$ in Chile, Colombia, Brazil, Mexico, Italy, Spain, Germany, and Japan to ensure validity and reliability. Students provided feedback on the survey's time, comprehensibility, user-friendly format, level of interest, and general suggestions. The final survey was adjusted according to pre-test results.

\section{Data collection and study setting}

Medical student collaborators, who were enrolled students at medical faculties within the nine surveyed countries, distributed the survey in each location via institutional emails, student associations, and social media using the non-probability convenience sampling technique. A total of 148 medical schools across nine countries (Chile, Colombia, Brazil, Mexico, Italy, Spain, Germany, and Japan) were included in the final analysis. The cross-sectional survey was conducted from June 22, 2020, to July 24, 2020.

\section{Data analysis}

Demographic characteristics and curricular changes were examined in absolute numbers and percentages. Students' satisfaction with in-person, hybrid and online teaching formats was compared using Chi-squared $\left(\chi^{2}\right)$-tests and visualized on a Likert-plot. The mean number of mental and physical 
health symptoms was compared across countries using $\chi^{2}$ tests and displayed on a world map. Changes in substance and drug use were displayed for each country. Multivariate logistic regressions explore the association of collected variables with depressed mood, insomnia, and headache. Adjusted odds ratios (AOR) and 95\% confidence intervals (CI) are presented. Data analysis was performed with STATA SE Version 15.1.

\section{Results}

\section{Curricula changes}

In the entire sample, students reported that their faculties implemented the following teaching modalities: $7 \%(\mathrm{n}=150)$ no teaching, 3\% $(\mathrm{n}=65)$ in-person, $23 \%(\mathrm{n}=531)$ hybrid, and $67 \%(n=1,534)$ online. Overall, 58\% $(n=1,324)$ reported a change / postponement in the academic duration and $45 \%$ $(n=1,024)$ in the number of academic evaluations. 36\% $(\mathrm{n}=826)$ reported a reduction and $57 \%(\mathrm{n}=1,294)$ a suspension of practical activities in academic health facilities since the onset of the pandemic. All results varied across countries. Students' satisfaction with the implemented teaching modalities varied significantly (Figure 1). Across all countries, students were equally satisfied with the teaching modality, quality, the evaluation system, and academic burden of inperson, hybrid, and online curricula. Students were more satisfied with the teaching quantity of in-person teaching $(\mathrm{M}=3.0, \mathrm{SD}=1.1)$ compared to hybrid $(\mathrm{M}=3.1, \mathrm{SD}=1.1)$ and online $(\mathrm{M}=3.2, \mathrm{SD}=1.1)$ teaching $\left(\chi_{(8, \mathrm{~N}=2,130)}^{2}=22.44, \mathrm{p}=.004\right)$. Students were generally pleased with their internet connection $(\mathrm{M}=2.5, \mathrm{SD}=1.2)$. Respondents educated under a hybrid curriculum $(\mathrm{M}=2.9, \mathrm{SD}=1.4)$ were more content with the local COVID-19 sanitary measures than in-person $(\mathrm{M}=3.5$, $\mathrm{SD}=1.2)$ or online $(\mathrm{M}=3.5, \quad \mathrm{SD}=1.3)$ teaching $\quad\left(\chi_{(8,}^{2}\right.$ $\mathrm{N}=2,130)=76.58, \mathrm{p}<.001)$. Across all dimensions, students were more unsatisfied with no teaching than other teaching modalities.

\section{Mental and physical health symptoms}

In the entire sample, at least every fifth student experienced negative changes in lifestyle habits: $21 \%(n=479)$ sleeping, $29 \%(n=661)$ eating, 22\% ( $n=502)$ weight. Even more frequently students witnessed undesirable shifts in mental health symptoms: $40 \%(\mathrm{n}=912)$ insomnia, $57 \%(\mathrm{n}=1,300)$ emotional irritability, and $47 \%(\mathrm{n}=1,072)$ instability, $41 \%$ ( $n=935)$ anhedonia, and 40\% ( $n=912)$ depressed mood. Similarly common were negative changes in physical health: $36 \%$ $(n=821)$ headache, $57 \%(n=1,299)$ ocular tiredness, and $49 \%$ $(\mathrm{n}=1,117)$ backache.

On average students reported $2.2(\mathrm{SD}=1.8)$ mental and $1.4(\mathrm{SD}=1.1)$ physical health symptoms that were new or intensified since the onset of the pandemic. However, mental $\left(\chi_{(40, N=2,280)}^{2}=228.56, \mathrm{p}<.001\right)$ and physical $\left(\chi_{(24, \mathrm{~N}=2,280)}^{2}=259.71\right.$, $\mathrm{p}<.001)$ health symptoms were unevenly distributed across countries (Figure 2). On the lower end, medical students in Japan only reported $0.8(\mathrm{SD}=1.2)$ mental and $0.5(\mathrm{SD}=0.7)$ physical health symptoms. In contrast, Colombian and Brazilian students displayed 2.7 ( $\mathrm{SD}=1.7)$ and 2.6 $(\mathrm{SD}=1.8)$ mental health symptoms, respectively. Physical health symptoms were especially frequent in Colombia $(\mathrm{M}=1.9, \mathrm{SD}=1.0)$, Chile $(\mathrm{M}=1.7, \mathrm{SD}=1.1)$, Mexico $(\mathrm{M}=1.6, \mathrm{SD}=1.1)$, and Spain $(\mathrm{M}=1.6, \mathrm{SD}=1.1)$.

\section{Substance and drug use}

Across all countries, $36 \%(\mathrm{n}=828)$ of students reported a reduction in their alcohol consumption, while $9 \%(n=210)$ reported an increase. However, regional differences exist as a surge in alcohol consumption was more frequent in Germany with $19 \%(n=102)$, Brazil with $16 \%(n=25)$, and Japan with $11 \%(n=16)$. Overall, smoking habits remained unchanged, given that $4 \%(n=96)$ of students increased and $5 \%$ $(n=135)$ reduced their smoking. Similarly, $3 \%(n=71)$ of respondents increased their consumption of cannabis whereas $7 \%(n=151)$ decreased it. Three percent $(n=77)$ of students increased their use of antidepressants, while $2 \%(n=48)$ diminished it. Notably is the surge of antidepressant use in Brazil with $13 \%(n=20)$ and Chile with $5 \%(n=27)$. The use of psychostimulants and other drugs remained largely unchanged across all countries (Figure 3).

\section{Variables associated with depressed mood, insomnia, and headache}

The multivariate regression (Table 2) suggests that female relative to male students were at higher risk to develop negative changes in depressed $\operatorname{mood}(\mathrm{AOR}=1.60, \mathrm{p}<.001)$, insomnia $(\mathrm{AOR}=1.40, \mathrm{p}<.001)$, and headache $(\mathrm{AOR}=2.36, \mathrm{p}<.001)$. Medical students in their last years of education compared to beginners were at a lower risk of developing mental or physical health symptoms. Students that participated in the care of COVID-19 patients were not at an increased risk to develop any of the three health symptoms. Students experiencing negative changes in their studying habits since the onset of the pandemic were at higher risk of erosions in mental and physical health - depressed $\operatorname{mood}(\mathrm{AOR}=2.10, \mathrm{p}<.001)$, insomnia $(\mathrm{AOR}=1.80, \mathrm{p}<.001)$, and headache $(\mathrm{AOR}=1.46$, $\mathrm{p}<.001)$. Similarly, students with changed/postponed curricula durations were more susceptible to negative changes in depressed $\operatorname{mood}(\mathrm{AOR}=2.13, \mathrm{p}<.001)$, insomnia $(\mathrm{AOR}=1.64$, $\mathrm{p}<.001)$, and headache $(\mathrm{AOR}=1.34, \mathrm{p}<.001)$ symptoms.

Changes in the teaching modality - online vs hybrid or in-person - were not significantly associated with health outcomes. Students that experienced changes in the academic duration were more susceptible to mental and physical health symptoms - depressed mood $(\mathrm{AOR}=1.15, \mathrm{p}=.218)$, insomnia $(\mathrm{AOR}=1.38, \mathrm{p}=.005)$, and headache $(\mathrm{AOR}=1.28, \mathrm{p}=.040)$. Reductions in the number of practical courses and exams were not associated with a significant change in mental or physical health symptoms. Medical students who were dissatisfied with their internet connection were more likely to develop depressed $\operatorname{mood}(\mathrm{AOR}=1.14, \mathrm{p}=.002)$, insomnia $(\mathrm{AOR}=1.07$, $\mathrm{p}=.115)$, and headache (AOR=1.18, $\mathrm{p}<.001)$. Accordingly, positive associations between the number of daily screen hours 


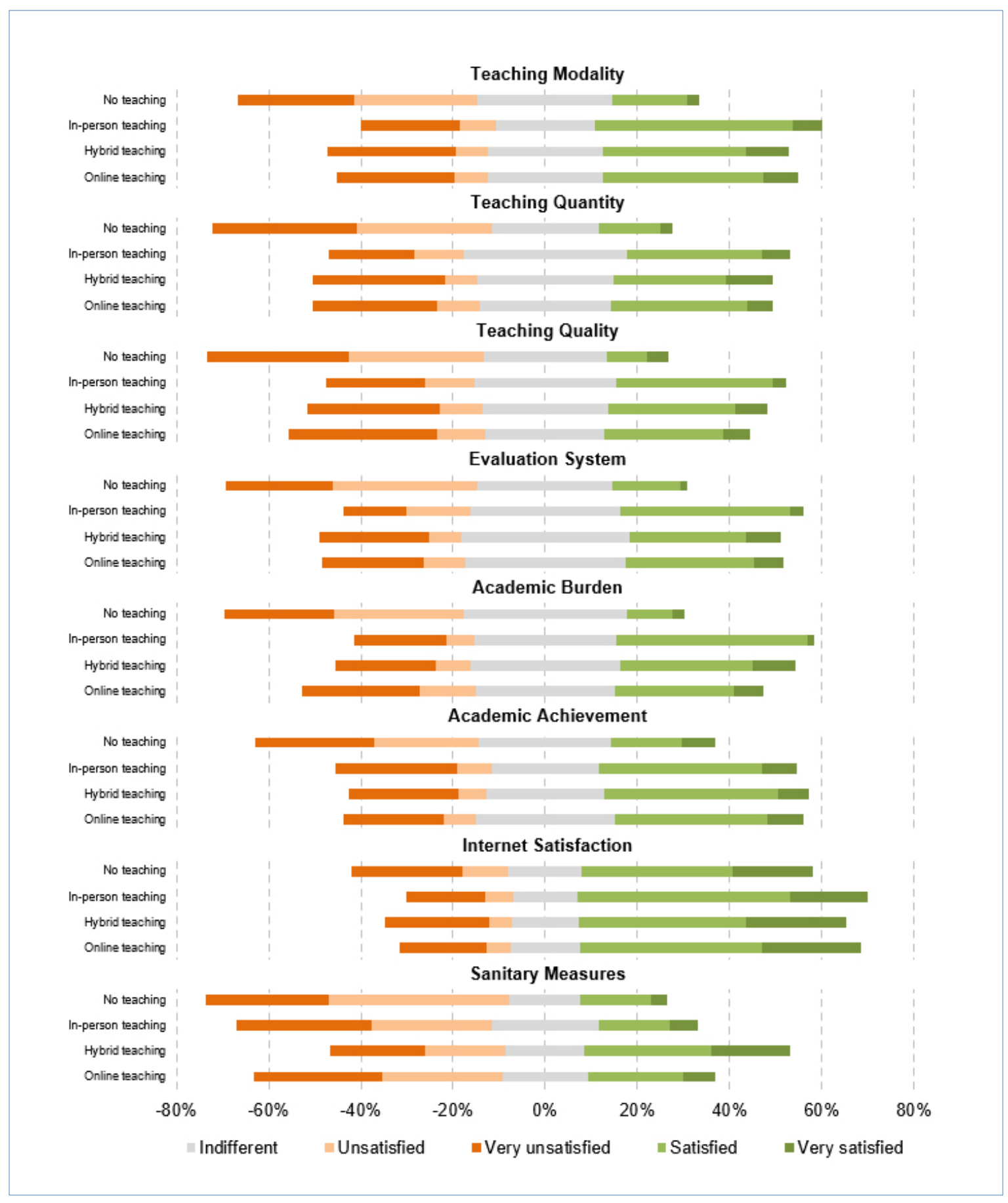

Figure 1. Medical students' satisfaction with in-person, hybrid, and online teaching formats

and all three outcomes were identified - depressed mood $(\mathrm{AOR}=1.09, \mathrm{p}<.001)$, insomnia $(\mathrm{AOR}=1.08, \mathrm{p}<.001)$, and headache $(\mathrm{AOR}=1.11, \mathrm{p}<.001)$.

Respondents stating an increased alcohol consumption were at a higher risk of developing a depressed mood $(\mathrm{AOR}=1.42, \mathrm{p}=.038)$ and insomnia $(\mathrm{AOR}=1.41, \mathrm{p}=.042)$.
Smoking was significantly correlated with new onsets and intensification of insomnia $(\mathrm{AOR}=1.92, \mathrm{p}=.004)$, whereas the consumption of cannabis was correlated to headaches ( $\mathrm{AOR}=1.75, \mathrm{p}=.040)$. Consumption of antidepressants was correlated to depressed mood $(\mathrm{AOR}=3.32, \mathrm{p}<.001)$ and headache $(\mathrm{AOR}=2.03, \mathrm{p}=.011)$. 
A Mean no. of mental health symptoms (out of 5 items)

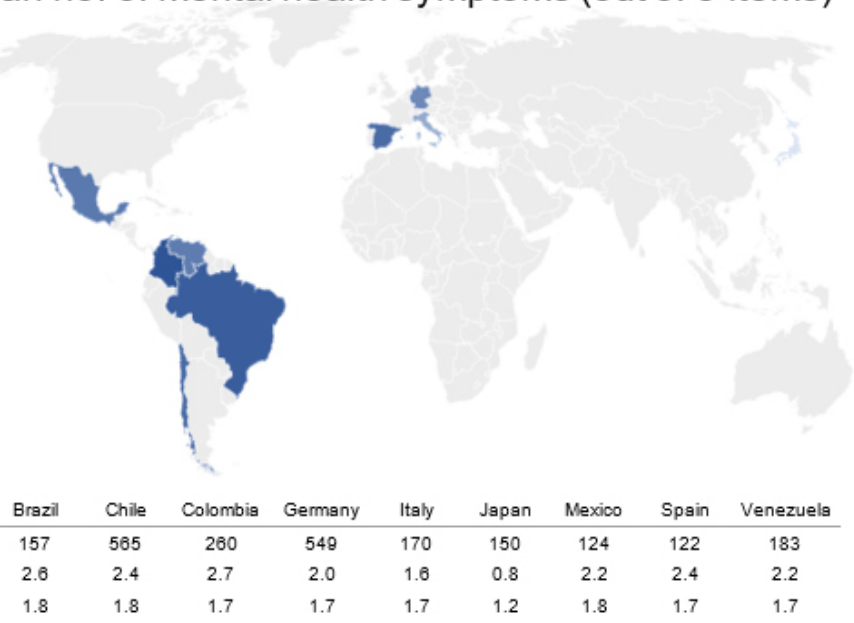

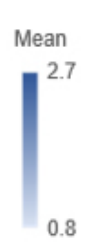

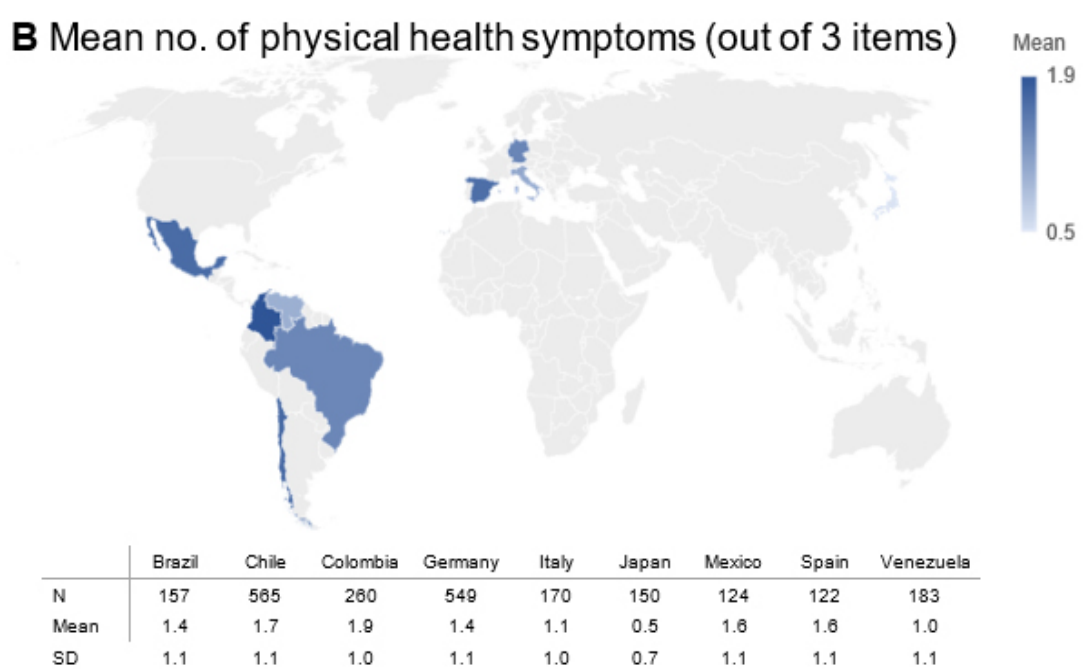

Surveyed mental health symptoms include insomnia, emotional irritability, emotional instability, anhedonia, and depressed mood. Surveyed physical health symptoms include headache, ocular tiredness, and backache.

Figure 2. Mean number of negative changes in (A) mental health and (B) physical health symptoms across countries 


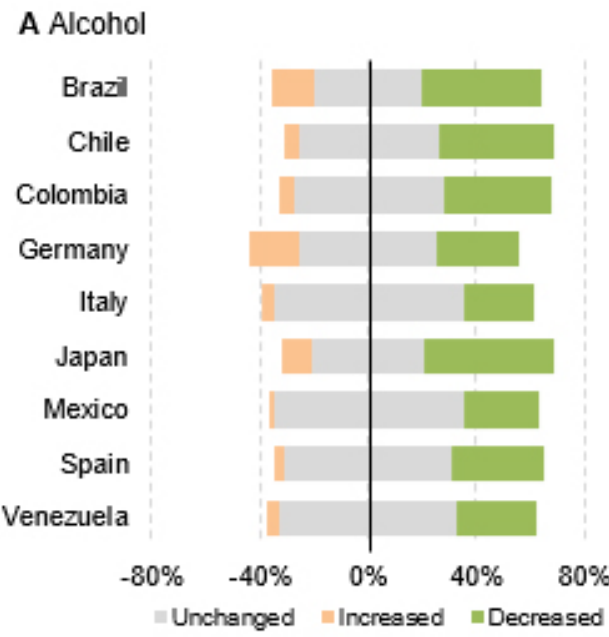

C Cannabis

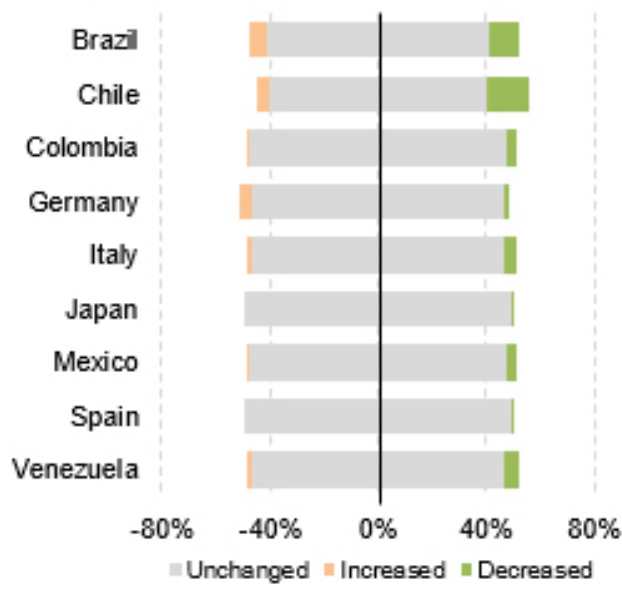

E Psychostimulants

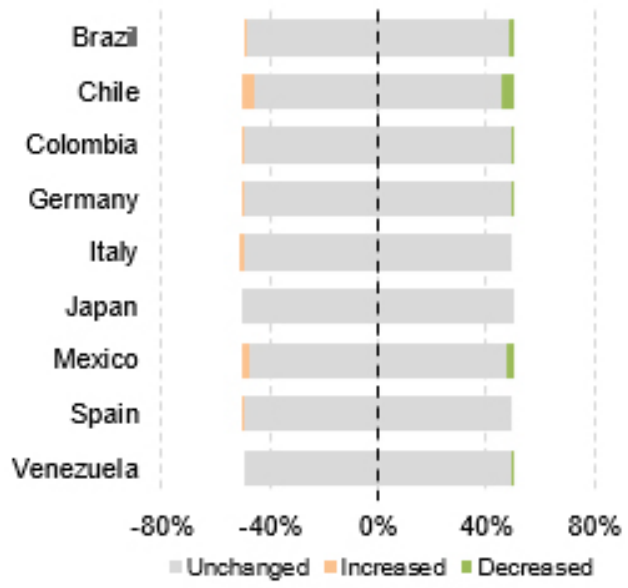

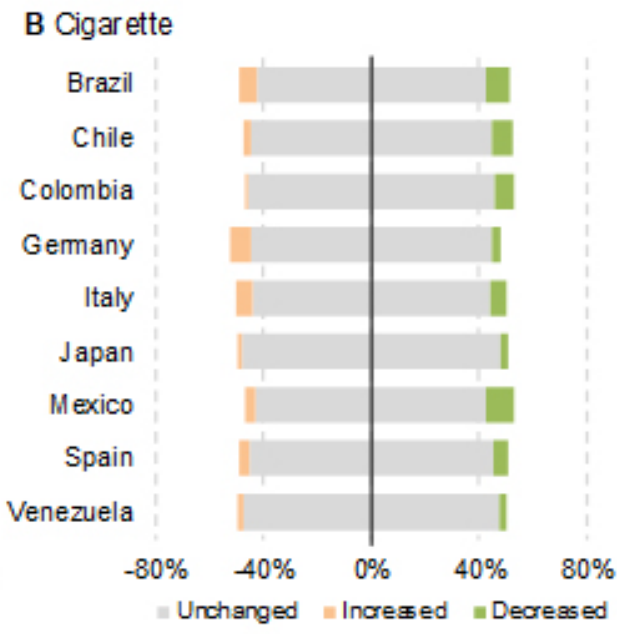

D Antidepressants

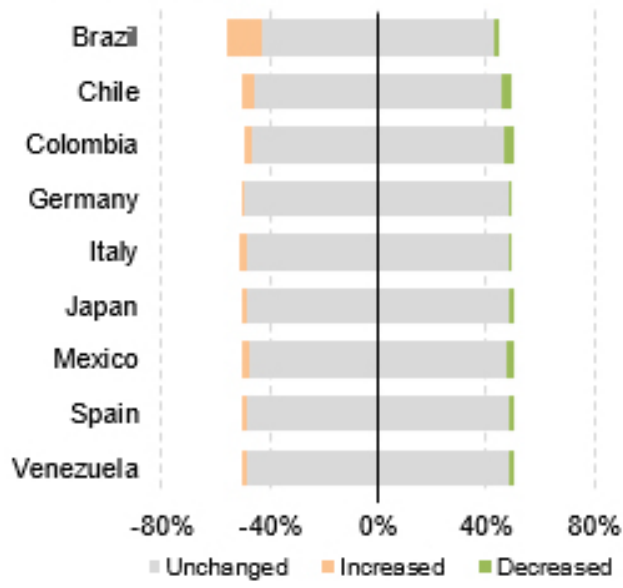

F Other drugs ${ }^{*}$

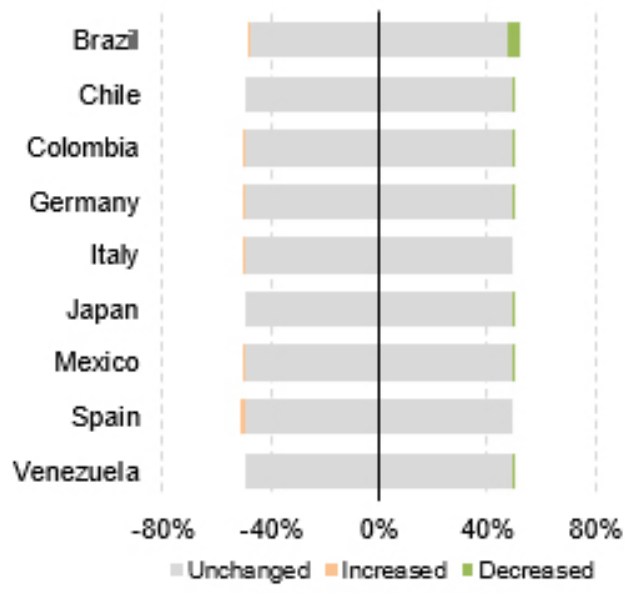

"Other drugs include cocaine, paste, heroin

Figure 3. Substance and drug use among medical students 
Michaeli et al. $\mathbf{M e d i c a l}$ education and mental health during COVID-19

Table 2. Multivariate logistic regression of factors associated with depressed mood, insomnia, and headache

\begin{tabular}{|c|c|c|c|c|c|c|c|c|c|}
\hline \multirow[b]{2}{*}{ Variable } & \multicolumn{3}{|c|}{ Depressed Mood a } & \multicolumn{3}{|c|}{ Insomnia ${ }^{a}$} & \multicolumn{3}{|c|}{ Headache $^{a}$} \\
\hline & AOR & {$[95 \% \mathrm{Cl}]$} & p-value & AOR & {$[95 \% \mathrm{Cl}]$} & p-value & AOR & {$[95 \% \mathrm{Cl}]$} & $\mathrm{p}$-value \\
\hline \multicolumn{10}{|l|}{ Gender } \\
\hline Male & 1 & [Reference] & & 1.00 & [Reference] & & 1.00 & [Reference] & \\
\hline Female & 1.60 & {$[1.30,1.96]$} & $p<.001$ & 1.40 & {$[1.14,1.71]$} & $p<.001$ & 2.36 & {$[1.90,2.92]$} & $\mathrm{p}<.001$ \\
\hline Other & 2.23 & {$[0.87,5.74]$} & $\mathrm{p}=.096$ & 2.57 & {$[0.93,7.13]$} & $p=.069$ & 1.76 & {$[0.50,6.23]$} & $\mathrm{p}=.383$ \\
\hline Year of study & 0.91 & {$[0.86,0.96]$} & $p<.001$ & 0.96 & {$[0.91,1.02]$} & $p=.156$ & 0.88 & {$[0.83,0.93]$} & $p<.001$ \\
\hline $\begin{array}{l}\text { The COVID-19 pandemic negatively } \\
\text { impacts your quality as a doctor? }\end{array}$ & 1.42 & {$[1.15,1.76]$} & $\mathrm{p}<.001$ & 1.27 & {$[1.03,1.56]$} & $p=.024$ & 1.15 & {$[0.94,1.42]$} & $p=.184$ \\
\hline $\begin{array}{l}\text { Satisfaction with local } \\
\text { COVID-19 sanitary measures }{ }^{b}\end{array}$ & 1.07 & {$[0.98,1.18]$} & $p=.149$ & 1.03 & {$[0.94,1.13]$} & $p=.491$ & 1.13 & {$[1.03,1.25]$} & $p=.010$ \\
\hline Online teaching & NA & NA & NA & 1.11 & {$[0.82,1.50]$} & $p=.494$ & 1.04 & {$[0.75,1.45]$} & $\mathrm{p}=.808$ \\
\hline Medical school delayed semester & 1.15 & {$[0.92,1.45]$} & $\mathrm{p}=.218$ & 1.38 & {$[1.10,1.72]$} & $p=.005$ & 1.28 & {$[1.01,1.61]$} & $p=.040$ \\
\hline Reduced no. of exams & 0.91 & {$[0.74,1.11]$} & $p=.344$ & NA & NA & NA & NA & NA & NA \\
\hline Thought about delaying studies? & 2.13 & {$[1.73,2.62]$} & $\mathrm{p}<.001$ & 1.64 & {$[1.34,2.00]$} & $\mathrm{p}<.001$ & 1.34 & {$[1.09,1.65]$} & $p=.005$ \\
\hline Negative change in study habits? & 2.10 & {$[1.73,2.55]$} & $\mathrm{p}<.001$ & 1.80 & {$[1.49,2.19]$} & $\mathrm{p}<.001$ & 1.46 & {$[1.20,1.78]$} & $\mathrm{p}<.001$ \\
\hline Internet satisfaction ${ }^{\mathrm{b}}$ & 1.14 & {$[1.05,1.23]$} & $\mathrm{p}=.002$ & 1.07 & {$[0.98,1.16]$} & $p=.115$ & 1.18 & {$[1.09,1.28]$} & $\mathrm{p}<.001$ \\
\hline Daily screen time (h) & 1.09 & {$[1.05,1.12]$} & $\mathrm{p}<.001$ & 1.08 & {$[1.05,1.11]$} & $\mathrm{p}<.001$ & 1.11 & {$[1.07,1.14]$} & $\mathrm{p}<.001$ \\
\hline Increased alcohol consumption & 1.42 & {$[1.02,1.98]$} & $p=.038$ & 1.41 & {$[1.01,1.95]$} & $p=.042$ & NA & NA & NA \\
\hline Increased cigarette consumption & 1.37 & {$[0.85,2.20]$} & $p=.191$ & 1.92 & {$[1.23,2.99]$} & $\mathrm{p}=.004$ & NA & NA & NA \\
\hline Increased cannabis consumption & NA & NA & NA & NA & NA & NA & 1.75 & {$[1.03,3.00]$} & $\mathrm{p}=.040$ \\
\hline Increased antidepressant use & 3.32 & {$[1.83,6.02]$} & $\mathrm{p}<.001$ & 1.39 & {$[0.81,2.41]$} & $\mathrm{p}=.235$ & 2.03 & {$[1.18,3.51]$} & $p=.011$ \\
\hline Increased psychostimulant use & 1.84 & {$[0.85,3.95]$} & $p=.121$ & 1.84 & {$[0.88,3.87]$} & $p=.108$ & 1.21 & {$[0.58,2.50]$} & $p=.613$ \\
\hline Increased use of other drugs ${ }^{c}$ & NA & NA & NA & 1.70 & {$[0.33,8.76]$} & $p=.525$ & 1.70 & {$[0.31,9.38]$} & $p=.545$ \\
\hline \multicolumn{10}{|l|}{ Country } \\
\hline Brazil & 1.00 & [Reference] & & 1.00 & [Reference] & & 1.00 & [Reference] & \\
\hline Chile & 0.74 & {$[0.48,1.13]$} & $p=.162$ & 1.02 & {$[0.68,1.52]$} & $\mathrm{p}=.932$ & 1.89 & {$[1.23,2.91]$} & $p=.004$ \\
\hline Colombia & 0.87 & {$[0.54,1.42]$} & $p=.585$ & 1.47 & {$[0.93,2.34]$} & $p=.101$ & 2.29 & {$[1.39,3.76]$} & $p<.001$ \\
\hline Germany & 2.00 & {$[1.24,3.23]$} & $p=.005$ & 1.06 & {$[0.67,1.66]$} & $p=.809$ & 2.04 & {$[1.25,3.33]$} & $p=.005$ \\
\hline Italy & 1.33 & {$[0.75,2.34]$} & $p=.325$ & 1.18 & {$[0.67,2.05]$} & $p=.571$ & 1.55 & {$[0.85,2.79]$} & $p=.150$ \\
\hline Japan & 0.53 & {$[0.29,0.98]$} & $p=.042$ & 0.43 & {$[0.23,0.80]$} & $p=.008$ & 0.50 & {$[0.24,1.01]$} & $p=.055$ \\
\hline Mexico & 0.79 & {$[0.46,1.35]$} & $p=.387$ & 2.01 & {$[1.20,3.38]$} & $p=.008$ & 1.47 & {$[0.84,2.57]$} & $p=.178$ \\
\hline Spain & 1.25 & {$[0.70,2.22]$} & $p=.446$ & 1.70 & {$[1.00,2.88]$} & $p=.049$ & 2.76 & {$[1.59,4.79]$} & $p<.001$ \\
\hline Venezuela & 0.95 & {$[0.57,1.58]$} & $\mathrm{p}=.841$ & 0.75 & {$[0.46,1.24]$} & $p=.265$ & 0.75 & {$[0.44,1.30]$} & $p=.305$ \\
\hline
\end{tabular}

a New onset or intensification of depressed mood, insomnia, or headache since the onset of the pandemic.

b Satisfaction of internet connection and local sanitary measures was assessed with a 5-point Likert scale from 1 ("very dissatisfied") to 5 ("very satisfied").

c Other drugs include cocaine, paste, heroin.

\section{Discussion}

This cross-sectional survey investigated students' experience with medical school curricula alongside their mental and physical health during the COVID-10 pandemic across nine countries. We observed that medical faculties shifted academic teaching to a virtual $(67 \%, \mathrm{n}=1,534)$ or hybrid environment $(23 \%, \mathrm{n}=531)$, whilst bedside teaching was suspended or cancelled $(93 \%, n=2,120)$. However, our findings indicate a mixed experience with virtual teaching. Education modality, quality, the evaluation system, and academic burden were evaluated similarly to in-person and hybrid teaching. Although we observed high levels of mental and physical distress, alcohol consumption declined whilst cigarette and cannabis use remained largely unchanged. Students' consecutively increased screen time was positively correlated to negative changes in depressed mood, insomnia, and headache.

\section{Medical education and COVID-19}

Medical hospitals were not only confronted with more infected COVID-19 patients but also had to maintain medical teaching. The medical curriculum had to rapidly incorporate new public policies whilst also equipping students with crucial hands-on skills and introducing them to clinical routine. The present study found drastic shifts in the academic curricula of medical schools. Similar to previous case reports and general expectations, classes were predominantly virtual or hybrid..$^{6-8,38}$ Differences across countries may partially be explained by the differential impact of the pandemic among countries and varying digital infrastructures. Online teaching provides students with similar theoretical knowledge as inperson curricula and also promotes self-paced learning. ${ }^{39} \mathrm{On}$ the other hand, laptops, phones, and other technology 
devices were found to be a source of distraction, are not equally accessible across all countries and sample groups, and seldom teach social skills - which are essential for the work of doctors. ${ }^{40}$ In our survey, $45 \%$ of students reported worsening of their study habits alongside frequent physical symptoms, which could adversely impact their concentration and learning abilities. Nonetheless, the observed changes in study habits and physical health symptoms could be equally caused by the transition to a virtual curriculum as well as public policies that limit social life. Medical schools could organize classes to prepare students for remote learning requiring adapted study habits - in the long run, this may strengthen resilience and foster successful academic adaptation during a pandemic.

Students' satisfaction with medical curricula across the surveyed countries were divergent. There was no difference in the students' satisfaction regarding teaching modality, quality, and quantity of in-person, hybrid, and online teaching. Students under an online teaching environment were less satisfied with the overall academic burden. Notably, across all examined dimensions, "no teaching" was evaluated worse than any of the other teaching formats. This result underlines that students want to continue their education and seek guidance from their university during the uncertain pandemic. Additionally, two-thirds of students across all countries were afraid that the direct and indirect effects of the pandemic would negatively impact their quality as a physician. In other words, certain parts of the medical curriculum ought not to be digitized. Bedside teaching, doctor-patient anamnesis, practical examinations, and laboratory classes are essential for the comprehensive training of emerging physicians. ${ }^{39,41}$ Medical schools must decide until when and to what extent the current virtual/hybrid medical curriculum will persist after the pandemic subsides. The pandemic might allow a transformation in medical education with the active participation of students in curricular innovation. Students should learn new technologies, such as telehealth, during their regular curricula. Students' overall satisfaction could be increased by establishing decentralized interactions in safe environments with patients to limit the risk of transmission of the virus.

\section{Medical students' mental and physical health}

Coherent with previous studies, our results support the association between pandemics and surges in physical and mental distress. ${ }^{3,42-45}$ Relative to medical student reference groups, we observed high levels of mental and physical health symptoms. This detected psychological pain could be caused by social distancing and quarantining measures that limit social life and be augmented by the novel digital/hybrid medical teaching. Previous studies found that both policies are associated with increased psychological distress. ${ }^{2-5}$ Physical and mental distress might be improved by the introduction of more advanced technologies, such as virtual clinical experiences. Students need to acquire tools to combat stressors within a social support environment. Resilience during COVID-19 is higher with coping strategies when students perceive a high level of social and emotional support and thereby ameliorate their mental health. ${ }^{46}$ Further studies are necessary to analyze to what magnitude medical students' deteriorated well-being persists beyond the pandemic.

As teaching transitioned to a virtual/hybrid curriculum, students inevitably had to spend more time in front of a screen every day. However, our results reveal a high correlation between daily screen time and depressed mood, insomnia, and headaches. This is in line with several studies confirming the relationship between display use and psychological distress as well as physical illnesses. ${ }^{47,48} \mathrm{~A}$ higher use of electronic devices was especially linked to depression, anxiety, and lower emotional stability rates. ${ }^{47,48}$ Furthermore, increased internet usage was identified as a risk factor to develop an addiction for patients with underlying psychological comorbidity to develop an addiction. ${ }^{49}$ Further studies reveal that screen time is a risk factor to develop a metabolic syndrome in a dose-dependent manner independent of physical activity. ${ }^{49}$ In contrast, a recent review underlines that regular physical activity has beneficial effects on depression and anxiety during the COVID-19 pandemic. ${ }^{50}$ Consequently, universities should facilitate and promote physical activities by a variety of means, e.g., offering online activity courses, enhancing access to sport facilities, or providing fitness community apps. Staying physically active during the COVID-19 pandemic would contribute to the attenuation of the side effects caused by the outbreak on mental health after the pandemic subsides. Consequently, online curricula should allow for sufficient breaks to facilitate screen absence. More strikingly, based on the findings of a metaanalysis, social isolation and loneliness have a comparable effect on mortality, such as with well-established risk factors for mortality. ${ }^{51}$ Taken together, there might be long-term consequences on the medical students' health. The transition to an online curriculum may accelerate existing inequities within a country and across nations. Access to a good internet connection is a prerequisite for online education, yet $25 \%$ of students reported a poor connection. A poor connection does not only hinder widespread adoption of virtual teaching, but is also a source of distraction, cultivates students' frustration, and inhibits learning success. ${ }^{52}$ Furthermore, a relatively poor internet connection might be a proxy for a lower socioeconomic status. Medical faculties must be aware of the direct and indirect consequences of novel policies on their students.

The current year's academic duration changed or was uncertain for more than half of the surveyed students. In accordance with expectations, this change and uncertainty were strongly and significantly associated with depressed mood, insomnia, and headache. Students may frequently perceive this external insecurity with worries about their short-term academic future, but also long-term career prospects. ${ }^{11,12}$ In line with expectations, practical teaching 
activities were frequently reduced or suspended. The absence of practical education coupled with hesitation encircling digital teaching formats could have intensified the observed emotional distress. ${ }^{39,41}$ Medical universities might react to students' worsened mental health by offering easily accessible psychological counselling and interventions. Moreover, the interaction with teachers, classmates, friends, and other social peers should be strengthened.

Results also suggest that mental health symptoms were more prevalent in the early stages of medical school compared to later stages. In countries such as Germany, Italy, or Spain, the pre-clinical stage is known to be especially workintensive and stressful for students, which could rationalize this finding. Alternatively, more mature students have already built a stronger social network at their university and could thereby possess more coping mechanisms to combat external shocks such as the COVID-19 pandemic. As a result, medical universities could introduce mentors for freshmen to provide social and specialized support.

Increased alcohol consumption was significantly associated with negative changes in depressed mood and insomnia. Such associations are commonly observed in previous literature. ${ }^{34,53}$ Based on studies investigating alcohol consumption after the SARS outbreak in 2003, these results must be reviewed very carefully. Short-term increases in alcohol consumption were maintained in the general public and among healthcare workers after the 2003 outbreak..$^{53}$ Similarly, results show that students displaying psychological disorders were prescribed or self-medicated more frequently with antidepressants. Antidepressants might not be sufficient to treat depressive symptoms. Generally, physician consultation is necessary to evaluate and diagnose a mental illness. After that, a combination of pharmacotherapy, a strong network of social support, and psychotherapy are necessary to combat underlying causes of mental illnesses in the long run. Therefore, virtual social peer networks and mentoring groups can help to increase and maintain social capital. ${ }^{19}$ However, the findings reveal that $36 \%(n=821)$ of the sample reported a reduction in their alcohol consumption. This might be explained by increased access barriers due to reduced opening hours and frequent lockdown policies.

\section{Limitations}

Limitations of this study are present. First, online survey biases impact our results. Self-selection bias of internet users and the gender unbalanced sample ( $68 \%$ female) limit the generalizability of results. Students could have been dishonest about reporting substance use, especially if such substances are illegal in their country. Second, mental health variables were not assessed with validated survey tools. Mental health outcomes were self-reported and, therefore, not clinically verified. Third, causality cannot be inferred given the cross-sectional survey design. Moreover, variations in the structure of medical education and licensing exams limit the comparability and generalizability of results across countries. In addition, participation in online surveys is limited by the respondents' access to the internet. As a result, results might over-report access to online/hybrid classes. Finally, findings only provide insight into health outcomes until July 24, 2020. Further studies are necessary to explore the long-term association between academic/societal changes and mental health status due to COVID-19.

\section{Conclusions}

The COVID-19 pandemic not only disrupted social and professional life but also drastically impacted academic teaching for medical students. Adding to existing evidence, this study confirms the high rates of mental and physical health burdens faced by medical students across all nine countries. Psychological distress was especially frequent for students with a poor internet connection. A prolonged academic year, increased alcohol and antidepressants consumption, and a higher screen time was associated with mental and physical symptoms. Policymakers and schools should be aware of these burdens, as non-traditional academic curricula may extend beyond 2021. The findings of the study implicate that students' mental health and medical education might be improved by ensuring high-speed internet connection. Moreover, daily screen time should be limited despite online education. In addition, access barriers allowing online contact to affected peers and mental health coaches should be lowered. However, even after the pandemic subsides and academic life returns to normality, the presented severe changes in mental health may persist. Therefore, targeted psychological interventions are crucial to meet students' health during and beyond the pandemic. Panel studies are required to examine the casual long-term implications of COVID-19 on mental health.

\section{Acknowledgements}

The authors would like to thank Mr Juan Pedro Ross and $\mathrm{Mr}$ Francisco Lopez for collaborating in the initial design of the study and all medical students who participated in this survey.

\section{Conflict of Interest}

The authors declare that they have no conflict of interest.

\section{References}

1. Shultz JM, Baingana F, Neria Y. The 2014 Ebola outbreak and mental health: current status and recommended response. JAMA. 2015;313(6):5678.

2. Galea S, Merchant RM, Lurie N. The mental health consequences of COVID-19 and physical distancing: the need for prevention and early intervention. JAMA Intern Med. 2020;180(6):817-8.

3. Pfefferbaum B, North CS. Mental health and the COVID-19 pandemic. N Engl J Med. 2020;383(6):510-2.

4. Mukhtar S. Psychological health during the coronavirus disease 2019 pandemic outbreak. Int J Soc Psychiatry. 2020;66(5):512-6.

5. Liu JJ, Bao Y, Huang X, Shi J, Lu L. Mental health considerations for children quarantined because of COVID-19. Lancet Child Adolesc Health. 2020;4(5):347-9.

6. Menon A, Klein EJ, Kollars K, Kleinhenz ALW. Medical students are not essential workers: examining institutional responsibility during the COVID19 pandemic. Acad Med. 2020;95(8):1149-51. 
7. Dedeilia A, Sotiropoulos MG, Hanrahan JG, Janga D, Dedeilias P, Sideris M. Medical and surgical education challenges and innovations in the COVID-19 era: a systematic review. In Vivo. 2020;34(3 Suppl):1603-11.

8. Almarzooq ZI, Lopes M, Kochar A. Virtual learning during the COVID-19 pandemic: a disruptive technology in graduate medical education. J Am Coll Cardiol. 2020;75(20):2635-8.

9. Soled D, Goel S, Barry D, Erfani P, Joseph N, Kochis M, et al. Medical student mobilization during a crisis: lessons from a COVID-19 medical student response team. Acad Med. 2020;95(9):1384-7.

10. Birch E, de Wolf M. A novel approach to medical school examinations during the COVID-19 pandemic. Med Educ Online. 2020;25(1):1785680.

11. Choi B, Jegatheeswaran L, Minocha A, Alhilani M, Nakhoul M, Mutengesa E. The impact of the COVID-19 pandemic on final year medical students in the United Kingdom: a national survey. BMC Med Educ. 2020;20(1):206.

12. Byrnes YM, Civantos AM, Go BC, McWilliams TL, Rajasekaran K. Effect of the COVID-19 pandemic on medical student career perceptions: a national survey study. Med Educ Online. 2020;25(1):1798088.

13. Smith CA. COVID-19: healthcare students face unique mental health challenges. BMJ. 2020;369:m2491.

14. DeWitt DE. Fighting COVID-19: enabling graduating students to start internship early at their own medical school. Ann Intern Med. 2020;173(2):143-4

15. Iacobucci G. COVID-19: medical schools are urged to fast-track final year students. Bmj. 2020;368:m1064.

16. Rasmussen S, Sperling P, Poulsen MS, Emmersen J, Andersen S. Medical students for healthcare staff shortages during the COVID-19 pandemic. Lancet. 2020;395(10234):e79-e80.

17. Chen CH, Mullen AJ. COVID-19 can catalyze the modernization of medical education. JMIR Med Educ. 2020;6(1):e19725.

18. Chao TN, Frost AS, Brody RM, Byrnes YM, Cannady SB, Luu NN, et al. Creation of an interactive virtual surgical rotation for undergraduate medical education during the COVID-19 pandemic. J Surg Educ. 2021;78(1):346-50. 19. Rastegar Kazerooni A, Amini M, Tabari P, Moosavi M. Peer mentoring for medical students during the COVID-19 pandemic via a social media platform. Med Educ. 2020;54(8):762-3.

20. Iancu AM, Kemp MT, Alam HB. Unmuting medical students' education: utilizing telemedicine during the COVID-19 pandemic and beyond. J Med Internet Res. 2020;22(7):e19667.

21. Comer BT, Gupta N, Mowry SE, Malekzadeh S. Otolaryngology education in the setting of COVID-19: current and future implications. Otolaryngol Head Neck Surg. 2020;163(1):70-4.

22. Raj S, Abu-Ghname A, Davis MJ, Maricevich RS. The COVID-19 pandemic: implications for medical students and plastic surgery residency applicants. Plast Reconstr Surg. 2020;146(3):396e-7e.

23. Go B, Rajasekaran K. Effect of COVID-19 in selecting otolaryngology as a specialty. Head Neck. 2020;42(7):1409-10.

24. Michaeli D, Keough G, Strotzer Q, Michaeli T. Digital medical education and students' mental health: effects of the COVID-19 pandemic in Germany; 2021 [cited 01 December 2021]; Available from: https://doi.org/10.1108 /JMHTEP-03-2021-0035.

25. Lai J, Ma S, Wang Y, Cai Z, Hu J, Wei N, et al. Factors associated with mental health outcomes among health care workers exposed to coronavirus disease 2019. JAMA Netw Open. 2020;3(3):e203976.

26. Shi L, Lu ZA, Que JY, Huang XL, Liu L, Ran MS, et al. Prevalence of and risk factors associated with mental health symptoms among the general population in China during the coronavirus disease 2019 pandemic. JAMA Netw Open. 2020;3(7):e2014053.

27. Rossi R, Socci V, Pacitti F, Di Lorenzo G, Di Marco A, Siracusano A, et al. Mental health outcomes among frontline and second-line health care workers during the coronavirus disease 2019 (COVID-19) pandemic in Italy. JAMA Netw Open. 2020;3(5):e2010185.

28. Spoorthy MS, Pratapa SK, Mahant S. Mental health problems faced by healthcare workers due to the COVID-19 pandemic-a review. Asian J Psychiatr. 2020;51:102119.

29. Walton M, Murray E, Christian MD. Mental health care for medical staff and affiliated healthcare workers during the COVID-19 pandemic. Eur Heart J Acute Cardiovasc Care. 2020;9(3):241-7.

30. Vindegaard N, Benros ME. COVID-19 pandemic and mental health consequences: Systematic review of the current evidence. Brain Behav Immu Immun. 2020;89:531-42.

31. Xiao H, Shu W, Li M, Li Z, Tao F, Wu X, et al. Social distancing among medical students during the 2019 coronavirus disease pandemic in China: disease awareness, anxiety disorder, depression, and behavioral activities. Int J Environ Res Public Health. 2020;17(14).

32. Kaparounaki CK, Patsali ME, Mousa DV, Papadopoulou EVK, Papadopoulou KKK, Fountoulakis KN. University students' mental health amidst the COVID-19 quarantine in Greece. Psychiatry Res. 2020;290:113111.

33. Li Y, Wang Y, Jiang J, Valdimarsdóttir UA, Fall K, Fang F, et al. Psychological distress among health professional students during the COVID-19 outbreak. Psychol Med. 2021;51(11):1952-4.

34. Nguyen HT, Do BN, Pham KM, Kim GB, Dam HTB, Nguyen TT, et al. Fear of COVID-19 scale-associations of its scores with health literacy and health-related behaviors among medical students. Int J Environ Res Public Health. 2020;17(11).

35. Lyons Z, Wilcox H, Leung L, Dearsley O. COVID-19 and the mental wellbeing of Australian medical students: impact, concerns and coping strategies used. Australas Psychiatry. 2020;28(6):649-52.

36. Wu S, Li Z, Li Z, Xiang W, Yuan Y, Liu Y, et al. The mental state and risk factors of Chinese medical staff and medical students in early stages of the COVID-19 epidemic. Compr Psychiatry. 2020;102:152202.

37. Zhan J, Sun S, Xie L, Wen Y, Fu J. Medical students' mental health, professional pride, and intention to work in the front-line during coronavirus disease 2019 pandemic. Zhong Nan Da Xue Xue Bao Yi Xue Ban. 2020;45(6):649-656.

38. Perez-Dominguez F, Polanco-Ilabaca F, Pinto-Toledo F, Michaeli D, Achiardi J, Santana V, et al. Lifestyle changes among medical students during COVID-19 pandemic: a multicenter study across nine countries. Health Educ Behav. 2021;48(4):446-54

39. Theoret C, Ming X. Our education, our concerns: the impact on medical student education of COVID-19. Med Educ. 2020;54(7):591-2.

40. Ruiz JG, Mintzer MJ, Leipzig RM. The impact of e-learning in medical education. Acad Med. 2006;81(3):207-12.

41. McGarry BJ, Theobald K, Lewis PA, Coyer F. Flexible learning design in curriculum delivery promotes student engagement and develops metacognitive learners: an integrated review. Nurse Educ Today. 2015;35(9):966-73.

42. Rajkumar RP. COVID-19 and mental health: a review of the existing literature. Asian J Psychiatr. 2020;52:102066.

43. Shigemura J, Ursano RJ, Morganstein JC, Kurosawa M, Benedek DM. Public responses to the novel 2019 coronavirus (2019-nCoV) in Japan: mental health consequences and target populations. Psychiatry Clin Neurosci. 2020;74(4):281-2

44. Reardon S. Ebola's mental-health wounds linger in Africa. Nature. 2015;519(7541):13-4.

45. Da BL, Im GY, Schiano TD. Coronavirus disease 2019 hangover: a rising tide of alcohol use disorder and alcohol-associated liver disease. Hepatology. 2020;72(3):1102-8.

46. Mai Y, Wu YJ, Huang Y. What type of social support is important for student resilience during COVID-19? A latent profile analysis. Front Psychol. 2021;12:646145.

47. Madhav KC, Sherchand SP, Sherchan S. Association between screen time and depression among US adults. Prev Med Rep. 2017;8:67-71.

48. Maras D, Flament MF, Murray M, Buchholz A, Henderson KA, Obeid N, et al. Screen time is associated with depression and anxiety in Canadian youth. Prev Med. 2015;73:133-8.

49. Christakis DA, Moreno MA. Trapped in the net: will internet addiction become a 21st-century epidemic? Arch Pediatr Adolesc Med. 2009;163(10):959-60.

50. Hu S, Tucker L, Wu C, Yang L. Beneficial Effects of Exercise on Depression and anxiety during the COVID-19 pandemic: a narrative review. Front Psychiatry. 2020;11:587557. 
Michaeli et al. - Medical education and mental health during COVID-19

51. Holt-Lunstad J, Smith TB, Baker M, Harris T, Stephenson D. Loneliness and social isolation as risk factors for mortality: a meta-analytic review. Perspect Psychol Sci. 2015;10(2):227-37.

52. Dost S, Hossain A, Shehab M, Abdelwahed A, Al-Nusair L. Perceptions of medical students towards online teaching during the COVID-19 pandemic: a national cross-sectional survey of 2721 UK medical students. BMJ Open. 2020;10(11):e042378.

53. Rehm J, Kilian C, Ferreira-Borges C, Jernigan D, Monteiro M, Parry CDH et al. Alcohol use in times of the COVID 19: Implications for monitoring and policy. Drug Alcohol Rev. 2020;39(4):301-4 